BULLETIN OF THE GEOLOGICAL SOCIETY OF AMERICA

VOL. 23, PP. 537-562

NOVEMBER 9, 1912

\title{
DEFLATIVE SCHEME OF THE GEOGRAPHIC CYCLE IN AN ARID CLIMATE ${ }^{1}$
}

BY CHARLES R. KEYES

(Presented before the Society December 29, 1911)

\section{CONTENTS}

Page

Introductory $\ldots \ldots \ldots \ldots \ldots \ldots \ldots \ldots \ldots \ldots \ldots \ldots \ldots \ldots \ldots \ldots \ldots, \ldots, \ldots, \ldots$

Controlling erosional agents under diverse climatic conditions........ 539

Preparation of rock materials for erosion. ................. 539

Effectiveness of water action in a moist climate.............. 540

Dominance of wind-scour in a dry climate.................. 540

Extent of ice scoring in a glacial climate.................. 541

Relations of glacial and arid erosion conditions................ 542

Essential features of aridity ............................. 543

Contrasted characteristics of arid and humid initial conditions.. . . . . 543

Surface offered to sculpturing agencies.................. 543

Antecedent rivers of desert regions....................... 544

Consequent drainage features........................ 545

Centripetal drainage.............................. 545

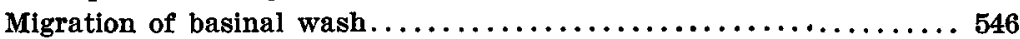

Initial relief features under aridity $\ldots \ldots \ldots \ldots \ldots \ldots \ldots \ldots \ldots .548$

Contrasted features of arid and humid topographic juvenility......... 548

Conditions generally postulated......................... 548

Youthful arid stage under deflation..................... 549

Ideal type of early arid stage......................... 550

Certain characteristic deflative features................... 551

Certain peculiarities of arid youth..................... 551

Mature stage of arid relief............................. 554

Deductive course of development...................... 554

Mature arid features under deflation.................... 554

Development of original drainage lines in desert ranges......... 555

Duration of arid maturity $\ldots \ldots \ldots \ldots \ldots \ldots \ldots \ldots \ldots \ldots \ldots \ldots \ldots .557$

Prevalence of old age in desert regions...................... 559

Postulated characteristics........................... 559

Topographic features of old age under deflation............. 559

Baselevel of eolian erosion............................... 559

Normal water action in desert regions...................... 560

Recapitulation.................................. 562

1 Recelved by the Secretary of the Society March 25, 1912.

Read by title under the caption "Geographic cycle in an arid climate: Should its development be by wind or water ?" December $29,1911$. 


\section{8 c. R. KEYES-THE GEOGRAPHIC CYCLE IN AN ARID CEIMATE}

\section{INTRODUOTORY}

Since as ordinarily developed the scheme of the geographic cycle postulates an upraised land surface exposed to stream action and other erosive influences peculiar to a humid climate, its designation "normal scheme" is perhaps as fitting as any other term possibly could be. The normal plan, however, has had to be modified to meet two special conditions. On the one hand it has been adapted to a glacial climate, and on the other hand to an arid climate. A number of writers have recently described these variations, but always with the essentials of the normal scheme conspicuously before them.

In all of these considerations stream action or water alone is regarded as the prime agency of regional leveling and lowering. That there should be need of distinctive treatment to meet the requirements of those special conditions of climate where the snows of winter do not all vanish in summer, and for those conditions of aridity where all basins do not overflow and the surface drainage never reaches the sea, gives rise to the query whether this solution of the problem actually obviates the difficulties presented. There is at once invited a comparison of the relative efficiencies of the several erosive processes under diverse climatic conditions.

One of the immediate results of such comparison is the suggestion whether instead of attempting longer to fit closely the two so-called special cases to a humid-climate standard we could not with great advantage recognize a different standard for each of the three sets of climatic conditions. Would it not be indeed more logical to develop separate cyclic phases along lines indicated by the effects of the dominant erosional process for each particular climate?

There is now no question but that in the past we have been prone to attach far too much general importance to the special products of the geologic processes as they operate in a humid climate and with which we are most familiar. A direct consequence has been to overlook, often almost completely, the workings of other geologic processes the effects of which are really quite extensive. Perfect familiarity with provincial facts and provincial conditions readily leads to too broad generalization. That relative to which we are pleased to denominate normal climate appears to be no exception to the rule.

The deflative scheme of an arid geographic cycle here outlined appears to be abundantly supported by data recorded elsewhere. These facts are set forth mainly in three recently published papers. Without reiterating 
here what they contain they may be pertinently considered in connection with the present discussion. Hence frequent reference is made directly to them. The present paper is the fourth of a closely connected series bearing especially on the arid regions of this country and the different phases of its eolative development. In the first account is described the remarkable rock-floors of the intermont plains of southwestern United States and northern Mexico. ${ }^{2}$ A second article, dealing with deflation and the relative efficiencies of erosional processes under conditions of aridity, describes the salient relief features of an area to all appearances now undergoing rapid denudation. ${ }^{3}$ The third memoir, ${ }^{4}$ on mid-continental eolation, refers especially to a broad region where deposition of wind-blown materials is believed to be taking place on a large scale. This fourth statement is an argument for the development of the geographic features in an arid region chiefly through means of wind-scour rather than stream action.

\section{Controlling erosional Agents under Diverse climatic Conditions}

\section{PREPARATION OF ROCK MATERIALS FOR EROSION}

Since the effects of erosion are made most conspicuous through the removal of loose.rock materials from the surface of the ground, the condition in which the degradational agencies find this rock-waste becomes a prime consideration. To the breaking down of rock-masses so largely influenced by climate the somewhat vague term "rock weathering" is applied. However, this term, familiar as it is, does not fully express the exact manner in which the transformation from the rock to rock-waste takes place.

The scheme of the normal geographic cycle premises moist-climate conditions, whereby the breaking down of the rocks at the surface is more largely chemical than mechanical. By implication at least the effect is regarded as a universal one, and little notice is taken of possible exceptions.

With greatest facility does chemical decay of rock-masses take place under conditions of heavy rainfall and warm climate. Yet long ago Von Richthofen ${ }^{5}$ drew attention to the fact that in cold or in dry climates the rocks display few signs of chemical decay. Russell ${ }^{6}$ further emphasized this feature when he said "that rock decay appears to be the

2 Bull. Geol. Soc. America, vol. 19, 1908, pp. 63-92.

s Ibid., vol. 21, 1910, pp. 565-598.

Ibld., vol. 22, 1911, pp. 687-714.

5 Führer für Forschungsreisende, p. 100. Berlin, 1886.

- Bull. Geol. Soc. Ameriea, vol. 1, 1890, p. 134. 


\section{0 c. R. KEYES-THE GEOGRAPHIC CYCLE IN AN ARID CLIMATE}

direct result of normally wet climatic conditions. In cold or arid regions the rocks are scarcely at all decayed." The production of rockwaste in desert lands through the process known as insolation is especially considered in another place. ${ }^{7}$ At the surface of the ground it is shown to be very largely mechanical, hardly at all chemical in nature.

\section{EFFEOTIVENESS OF WATER ACTION IN MOTST CLIMATE}

Those climatic conditions which tend to make of water action a most effective erosive agent, that in a humid land make it appear to be the sole process of general degredation, and that make it seem the only universal erosional activity are the very conditions which tend to obscure the effects of the erosional agencies which are most pronounced in a glacial climate and in an arid climate. Attempt to ascribe all erosion to stream action militates not so much against fact as it,marks a distinctive period in the history of erosive thought. The composite effects in humid as well as in both arid and glacial climates remain to be properly analyzed. The factor of relative efficiencies of each has to be determined in every region.

If water be the dominant erosional power in a moist climate it does not necessarily follow that less water is the sole erosive force in either dry or glacial climates.

\section{DOMINANCE OF WIND-SCOUR IN A DRY CLIMATE}

Notwithstanding the fact that during the past decade the wind in the capacity of a potent agent of general erosion has come to be recognized more and more universally, there still lingers a certain reluctance to admit its effectiveness in specific cases or its high relative rank among the degradational processes. Even in instances in which the climatic conditions are such as almost to preclude water action, where the annual rainfall is so small as to be almost negligible, stream work is still given first place and wind work a very subordinate place.

That wind-scour in an arid land should be considered not only the dominant erosional activity, but under the peculiarly favorable conditions for its operations more potent and rapid in its effects than is water action in a normal, wet country is a quite recent deduction, but one which seems to be amply supported by many observations. More fully to appreciate the enormous extent of eolation, it is necessary only to peruse the later publications of certain astute observers who have actually lived in desert lands, although in this country this subject has not received the attention that it seems to deserve. Of these mention

7 Bull. Geol. Soc. America, vol. 21, 1910, p. 569. 
may be made of the work of Obruchew, ${ }^{8}$ in central Siberia; of Walther, ${ }^{9}$ in north Africa; of La Touche, ${ }^{10}$ in the western Rajputana, in India; of Bergis and Irchenko, ${ }^{12}$ in the region about the Sea of Aral and on the Kirghiz steppes; of Passarge ${ }^{13}$ and of Davis, ${ }^{14}$ in the South African veldt; of Penck ${ }^{15}$ of Hundhausen ${ }^{18}$ in southern France; of Barron, ${ }^{17}$ in eastern Egypt, and of Blackwelder, ${ }^{18}$ in Wyoming.

Recent investigations in arid and semi-arid countries appear to demonstrate beyond all shadow of doubt that as a denuding, transportive, and depositional power the wind is not only fully competent to perform such work, but that it is comparable in every way to water action in a moist climate. As lately noted, ${ }^{18}$ it is significant that most of the broad intermont plains of the Southwestern Desert, for instance, should be areas of rapid degradation instead of aggradation, as is shown by their remarkable rock-floors, that the little normal water action therein should be confined to the loftier mountains, and that the general plains surface should be so little affected by stream corrasion. General desert leveling and lowering must find for their chief sculpturing agency something other than stream action. All things considered, deflation, or windscour, in arid lands not only appears to be the principal erosional process, but water action surprisingly subordinate.

Under conditions of aridity the relative efficiencies of wind-scour and water action may be roughly measured by the circumstance that the total volume of rock-waste brought down by storm waters from a desert range in a year may be removed by the winds in a single day. What general erosion by means of water is in a wet climate, eolation is under conditions of arid climate.

\section{EXTENT OF IOE SCORING IN A GLACIAL OLIMATE}

Erosion by ice under conditions of a true glacial climate is probably not nearly so vigorous, widespread, or important as it has been thought to be. Further, it may be questioned whether in the case of great continental ice-fields there is sufficient motion except near the melting mar-

\footnotetext{
${ }^{8}$ Verh. Imp. min. Gesellsch., St. Petersburg, vol. xxxili, 1895, p. 260.

- Das Gesetz d. Wüstenbildung im Gagenwart u. Vorseit, 1900.

10 Mem. Geol. Survey India, vol. xxxv, 1902, p. 10.

11 Pedologie for 1902 , p. 37.

10 Ann. geol. min. Russie, vol, vil, pt. 1, 1904, p. 43.

${ }^{13}$ Zeitsch. d. deuts, geol. Gesellsch., vol. lvi, Protokol, 1904, p. 193.

14 Bull. Geol. Soc. America, vol. 17, 1906, p. 435.

${ }^{15}$ American Journal of Science (4), vol, xix, 1905, p. 167.

${ }^{16}$ Globus, vol. cx, 1906 , p. 46.

17 Topography of Sinaf, western portion, 1907, p. 17.

18 Journal of Geology, vol. xvif, 1909, p. 429.

${ }^{10}$ Bull. Geol. Soc. America, ,ol, 21, 1910, p. 587.
} 
gins to produce notable erosion effects. In the adaptation of the normal humid-climate scheme of the geographic cycle to that of a glacial climate the conditions postulated have not been those of a truly glacial climate, but those of a mountainous region where glaciers are present, which is a very different thing.

The marked distinction between mountain glaciers and continental glaciers, or inland-ice fields, is fundamental. This is especially emphasized by Hobbs. ${ }^{20}$ Physiographically this distinction is far-reaching. The climate in the one case is not a glacial climate at all. The vigor and extent of ice scoring is more than commensurate with that which is displayed by the other. If anything, the absolute amount of abrasion is very much less in the last mentioned instance.

Continental glaciers seem to present conditions that are essentially desert conditions. The advancement of the ice-margin is probably more rapid through the constant outward drifting of the fine dry arctic snows than by any general motion of the ice itself. Recent observations in Greenland and Antarctica seem to leave little doubt of the existence of anticyclone areas over these inland-ice fields. Nansen ${ }^{21}$ and Peary ${ }^{22}$ in particular call attention to it in the north, while Shackleton ${ }^{23}$ furnishes complete evidence of the existence of a South Polar anticyclone, which 20 years before had been advocated by Murray. ${ }^{24}$ The drifting of the aretic snows is in all respects identical with the shifting of desert dusts and sands.

Formulated strictly according to boreal conditions and not on what is really a humid-climate basis, the commonly recognized scheme of a geographic cycle in a truly glacial climate needs radical revision. It may be that the glacial cycle could be with great advantage regarded as an arid cycle.

\section{Relations of glacial and arid Erosion Conditions}

In the paper read before the Geological Society in $1908^{25}$ I incidentally compared the most striking effects of deflation in the desert with those of the winter blizzard on our northern prairies, where fine ice-dust and ice-sands take the place of mobile comminuted rock-waste. Were it posssible to extend the blizzard a week or a month, or repeat it at short intervals for a longer period instead of a single day, the general plana-

\footnotetext{
20 Characteristics of existing glaciers, 1911, p. 6 .

2t First Crossing of Greenland, vol. if, 1890, p. 496.

Geographical Journal, vol, x, 1898, p. 233.

23 Heart of the Antarctic, vol. ii, 1910, p. 18.

24 Geographical Journal, vol. H1, 1893, p. 1.

25 Bull. Geol. Soc. America, vol. 21, 1910, p. 582.
} 
tion effects might be soon rendered quite conspicuous and even the eolic erosion of the protruding rock hills might soon appear appreciable.

The association of the origin of the continental glaciers with eolic activities is no doubt more intimate and far-reaching in its physiographic bearing than might be at first glance supposed. During a greater part of the year arctic conditions are essentially desert conditions. The identity and nature of the rock weathering in the two climates has been already noted. The peculiar dry, powdery character of arctic snows are comparable in all respects to the fine dusts and sands of arid regions. In both instances the main effects of the wind on the loose materials are the same. Until the dry snows, through partial melting, consolidate into ice, they remain in the same condition as desert dusts before they become exposed to moisture. That the one should accumulate into vast continental ice-fields and the other into vast evensurfaced mantles of continental sedimentaries is a fact which strictly accords with the theoretic expectations of eolic action.

It appears that considerably over one-half of the land area of the globe is profoundly affected by eolic agencies. Murray ${ }^{28}$ estimates that not less than one-fifth of the land surface is occupied by desert. At least another one-fifth is subject to greater or less accumulations of continental deposits of one sort or another in which wind-borne dusts form no inconsiderable part. ${ }^{27}$ Perhaps another one-fifth is or was within recent geological times covered by snow-fields and physiographically is to be considered as truly desert as the Sahara.

\section{Essential Features of Aridity}

The peculiarities of an arid climate are generally described in terms of normally humid conditions. Contrasted with those of moist climate they have been lately especially characterized by Davis. ${ }^{28}$ With particular reference to southwestern United States they have also been briefly noted by me. ${ }^{29}$ To these papers further reference is subsequently made.

\section{Contrasted Characteristics of arid and humid initial Stages}

SURFACE OFFERED TO SCULPTURING AGENCIES

Although the earth's crust with any structure, any form, and any altitude is postulated in the beginning for the normal or moist geographic cycle, the ideal and most complete cycle demands a recently upraised

\footnotetext{
sefence, n. s., vol. xvi, 1890, p. 106.

${ }^{27}$ Bull. Geol. Soc. America, vol. 22, 1911, p. 688.

28 Journal of Geology, vol. xill, 1905, p. 382.

- Bull. Geol, Soc. America, vol. 21, 1910, p. 568.
} 


\section{C. R. KEYES-THE GEOGRAPHIC CYCLE IN AN ARID CLIMATE}

peneplain. Singularly enough, no large peneplain is known that still remains near the baselevel with respect to which it was worn down. On the hypothesis of regional lowering and leveling by stream action, great and even unsurmountable difficulties are at once met with in attempting to explain satisfactorily the larger relief features of deserts.

Under conditions of aridity and with wind-scour as the chief denuding power, there need be no recent regional uplifting in order to initiate the arid cycle of erosion. The affected area may be an old plain of peneplain-like aspect, or it may be a vast plains surface frequently interrupted by mountain ridges. Whether it could be ever an area occupied entirely by lofty mountains is very questionable. Altitude, however, is practically a negligible factor. The initial heights of some deserts were doubtless several thousands of feet above sealevel. In view of the possibility of desert-leveling, the flat-topped Bural-bas-tau and the associated plateau-like highlands in the Tian Shan range in Turkestan need reconsideration, as Davis well observes. Because of the strong possibility of its formation above baselevel in a region of inland drainage, Friederichsen $^{30}$ expresses objection to regarding it as a once low-lying peneplain, as urged both by Davis ${ }^{31}$ and Huntington. ${ }^{32}$ In southwestern United States, as represented by the remnantal plateau of the Mesa de Maya, the initial surface of the desert of that region must have been at least 8,000 to 10,000 feet above sealevel. The high South African deserts offer other examples.

On the other hand, desert lowering by the wind goes on below the level of normal peneplanation, not perhaps indefinitely below normal baselevel, provided the sea be kept out, as urged by Penck, ${ }^{33}$ but some little distance below sealevel, until stopped by ground-water level, as apparently in the cases of the Death and Imperial valleys, in California. By deflation an arid cycle could be initiated on an old peneplain without any change in elevation.

The objections to ascribing a possible initiation of an arid cycle in a mountainous region I have already pointed out. ${ }^{34}$

\section{ANTECEDENT RIVERS OF DESERT REGIONS}

On the basis of the normal cycle, the drainage features, or rather the lack of them, in arid regions appear utterly inexplicable. Elevation of surface, which is so all important in the introduction of a new cycle in

\footnotetext{
so Petermann's Mittellungen, vol. xlix, 1903, p. 136.

st Appalachia, vol. $x, 1904$, p. 277.

${ }^{32}$ Carnegle Institution Publications, No. 26, 1905 , p. 157.

$\$$ American Journal of Science (4), vol. xix, 1905, p. 167.

a Bull. Geol. Soc. America, vol, 21, 1910, p. 589.
} 
the moist climate, should in a dry climate have little direct influence if an eolic hypothesis be followed. This inference all observations seem to support.

The only evidences of antecedent drainage persisting against regional deformation and aridity are presented by the few very largest rivers which have their headwaters beyond arid limits and merely cross the desert on their way to the sea. They receive little or no augmentation to their waters within the area of the dry region. Entirely apart from the desert should these through-flowing streams be considered. The Rio Colorado, the Rio Grande, and the Rio Pecos in the arid country of southwestern United States, the Nile in northeastern Africa, and similar rivers really exert small influence in the general lowering of the lands through which they pass. In the cases of all other streams which in a humid climate would be classed as antecedent rivers all vestiges would be soon lost with the initiation of the arid cycle. Their disappearance would be not only because they had merely dried up, but for the reason that their entire valleys had blown away.

\section{CONSEQUENT DRAINAGE FEATURES}

Consequent drainage, which according to the humid-climate idea must prevail, is in several respects peculiar. It is doubtful whether it should be called consequent drainage at all. It is certainly not consequent drainage as it is understood in a moist-climate region. In a high-lying mountainous desert, such as is displayed in the province already noticed and in the Mexican tableland, whatever drainage there may be is mainly of the sheetflood order. ${ }^{85}$ Even the streams coming down from the mountains tend to assume this character as soon as they reach the plains of the piedmont, as has been so graphically described by McGee. ${ }^{36}$

Certain peculiarities presented by these streams of the mountains are more fully discussed further on.

\section{CENTRIPETAL DRAINAGE}

The development of the present so-called consequent drainage of arid regions may not be necessarily, as has been urged, through the withering away of the lower reaches of streams belonging to a previous moist cycle. Neither may the independent centripetal systems belong to as many basins of initial deformation; that they should so belong is a necessary deduction of the moist-climate hypothesis. On the basis of an arid climate and a development of intermont basins through deflation instead

${ }^{25}$ Bull. Geol. Soc. America, vol. 19, 1908, p. 78 .

Bull. Geol. Soc. America, vol. 8, 1897, p. 87. 


\section{6}

of through recent deformation, a very different explanation is made possible and probable.

If it be postulated that the high-lying surface of such a region as the northern Mexican tableland, already referred to, was at the beginning of the arid cycle a plain, an upraised peneplain possibly; that its major folding and faulting were quite ancient, mainly prior to peneplanation, and this seems highly probable $;^{37}$ that the present intermont plains represent the belts of weak rock undergoing vigorous deflation, as their rock-floors indicate, and that in consequence the mountain belts of resistant rock are now rapidly being brought into stronger and stronger relief, as all observation goes to show, centripetal drainage must be advancing and expanding as the mountain ranges become relatively higher. Such drainage systems are growing rather than withering.

\section{MIGRATION OF BASINAL WASH}

General misconception has long prevailed concerning the derivation and composition of the basin soils of arid regions. It is frequently stated that the smooth intermont plains are formed by the wash from their highland rims. The valleys of the Great Basin are notable examples. Concerning this region this view has been expressed by nearly every one who has written on the geology of this district during the past 30 years. The best statement of this impression is that by Russell. ${ }^{88}$ Even so late as the past year an eminent geographer ${ }^{39}$ has seriously emphasized this old notion. Enormous depths are attributed to the wash in the central parts of these intermont basins. Estimates of 3,000 to 4,000 feet are not infrequent. The contiguous mountain ranges are considered as "buried up to their shoulders." This conclusion is the direct result of applying the normal humid-climate principles to such regions. In accordance with the same principles the sides of each basin often to the mountain crests are regarded as initial slopes of local deformation, which lead the wash of the local sporadic rains toward the central depression, whose lowest point serves as the baselevel for the basin. With this interpretation the facts do not seem very well to agree. Expected verification of hypothesis in the field is not only not realized, but there is complete surprise at its manifest invalidity.

The arroyos, or drainage channels of the desert ranges, do not appear to be the notable wash carriers that they are sometimes thought to be. Plain with beveled rock-floor and mountain with bare rocky sides sharply

87 Proc. Iowa Acad. Scl., vol. xlii, 1908, p. 221.

\$8 Geological Magazine, decade iil, vol. vi, 1889, p. 242.

${ }^{3}$ Harper's Magazine, vol. cxxill, 1911, p. 54. 
meet, and the great, thick, alluvial fans which one expects to encounter on every hand as the intermittent streams leave the highlands, are generally found to be singularly inconsequential. In place of huge fans miles in areal extent, hundreds of feet in thickness, and cubic miles in volume, which one is led to anticipate, their usual size and importance are almost ridiculously insignificant. Instead of vast extent and great bulk, examination shows that in a few days a steam-shovel and a train of cars could often remove every vestige down to bedrock.

The fact of the absence of thick wash accumulations in the central parts of many, if not of the majority, of intermont basins is strangely at variance with the assumption that the highland rims of bolson plains are eventually carried down by the rains and permanantly deposited in the lowest depressions. It appears that not only are many of these intermont plains not deeply. covered by washed-in rock-waste, but that they are only veneered with soil. ${ }^{40}$ The exceptionally dry Mojave Basin, in southeast California, seems to be a good example, if there be one, of an intermont plain so situated as to receive centrally the wash from a lofty rim because it is bounded on one side by the high wooded Sierra Nevada and on another side by the Sierra Madre. Moreover, the various low desert ranges within its boundaries are among the best instances known of "Iost" or "buried" mountains. Yet nowhere in all of this desert is it more clearly shown that the basin floor is not deeply covered by rockwaste. Not only do the mountains and hills display the beveled edges of the strata beneath, but many square miles of its plains surface, even in its central part, are so thinly covered by soil that the underlying rocks are everywhere well exposed. The bedrock surface is, as I have elsewhere shown, ${ }^{41}$ itself an even plain. This fact was long ago brought out in the geological descriptions of the region before its true significance was understood. Hershey ${ }^{42}$ is especially explicit on this point, and more recently Baker ${ }^{43}$ gives additional data of the same sort.

The records of deep drill-wells put down in various portions of arid America are often interpreted in support of the hypothesis that the intermont basins are deeply filled with rock-waste recently brought in by the rains. When critically examined, these drill-logs are found to be very misleading. In the majority of cases the great part of a drill-section is discovered to be in but slightly indurated Tertiary or Cretaceous or even Carboniferous deposits. Citing a specific instance: It was

\footnotetext{
40 Bull. Geol. Soc. America, vol. 19, 1908, p. 63.

41 Trans. American Inst. Mining Eng., vol. xl, 1909, p. 697.

${ }^{2}$ Univ. California Pub., Bull. Dept. Geol., vol. ili, 1902, p. 4.

43 Ibid., vol. vi, 1911, p. 333.
} 


\section{C. R. KEYES-THE GEOGRAPHIC CYCLE IN AN ARID CLIMATE}

claimed for the deep well at Albuquerque, New Mexico, that its 2,000 feet of depth were entirely in wash materials, whereas later, more careful and discriminating examination of the data clearly showed that scarcely 200 feet of the entire depth could be so considered. Similarly, certain deep drill-holes in southern Arizona are now known to have penetrated mainly tilted Tertiary beds instead of enormously thick wash deposits of quite recent date.

\section{INITIAL RELIEF FEATURES UNDER ARIDITY}

As already mentioned, there are two relief extremes on which an arid climate may be considered as imposed. They are a plain and a moderately mountainous surface. For obvious reasons a region of lofty mountains seems to be precluded. In the first instance the region is essentially a peneplain, although deprived of its streams. In the second case there is considerable diversity of relief, but no sharp, local contrasts such as are presented in a moist country in the beginning of a new cycle of erosion.

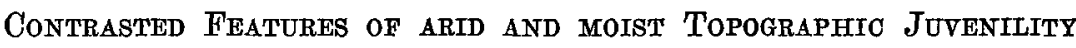
CONDITIONS GENERALLY POSTULATED

As the early stage of the normal geographic cycle is commonly regarded, the relief is ordinarily and rapidly increased by the incision of consequent valleys from the trunk rivers that flow to the sea. In the early stage of the arid cycle the relief is considered, on the hypothesis of water action, to be slowly diminished by the removal of waste from the highlands and its deposition on the lower gentler slopes and on the basin beds of all of the separate centripetal drainage systems. In consequence all the local baselevels are thought to rise, and the areas of deposition are given a nearly level central floor of fine waste. Streams, floods, and lakes, then, are made the chief agencies in giving form to the aggraded basin floors, as well as to the dissected basin margins in the early stage of the cycle. In illustration the Great Basin is commonly pointed out. The winds are sometimes conceded to have some importance, but in the youthful stage wind-blown hollows are claimed to be not likely to be formed. For the normal headward growth of many subsequent streams it is explained that in the arid cycle such streams have smaller opportunity for development because all the belts of weak structure under the basin deposits are buried out of reach.

Clearly these statements are the result of deduction based on the consideration of conditions as they prevail in a moist climate rather than of generalization supported by long continued observations in a dry cli- 
mate. One of the most serious objections to the development of desert landscapes by water action is the utter discordance between the necessary consequences of the moist-climate hypothesis and the facts actually observed.

\section{YOUTHFUL ARID STAGE UNDER DEFLATION}

On the basis of wind-scour action little that is ordinarily postulated for the early stage of the geographic cycle really obtains. The potency of water-work is found to be very greatly overestimated. The permanency of the deposits transported by the rains from the highland rims to the central lowlands of the intermont plains seems fanciful. The rising of the local baselevels appears to be poorly supported by facts. The development of drainage systems nowhere agrees with direct observation.

In the early stage of the arid cycle the relief seems to be rapidly increased by the hollowing out of broad flat-bottomed troughs or basins, laterally bordered by steep-sided, sharp-ridged mountain ranges. The air-streams accomplishing this work are hundreds of miles wide instead of a few hundreds of feet, as in the case of rivers; consequently the surface worked over is comparable to the channels of broad, shallow streams. Sharply incised topography so characteristic of humid lands is, therefore, impossible. General lowering is controlled partly by the proportions of weak and resistant rocks, partly by the extent and frequency of the faulting and other deformations of all previous time. Local conditions are sufficiently variable to enable the general lowering process to go on independently in the different basins, and the general leveling goes on also regardless of the relations of the denuded surface to sealevel. From the very beginning plains-forming is the most characteristic feature of desert-leveling. As the mountains become higher and higher normal water action increases on their sides, imparting to them something of the appearance of stream-graved surfaces. The relatively scant amounts of waste materials brought down and spread out from time to time at their bases are so rapidly removed by the winds that there is at any one time little actual accumulation. Rarely do sporadic cloudbursts carry notable quantities of the finer waste into the centers of the larger basins, there eventually to constitute thick deposits. Moving sand dunes are momentary phenomena. Permanent deposition of the finer waste goes on only beyond the boundaries of the desert in the bordering semi-arid belts or in the adjoining seas.

In the case of the youthful relief stage in a normally humid land its maturity is commonly regarded as approaching when dissection has gone on until the major drainage divides have lost some of their height and sharpness of outline and all elevations have begun to assume a notably 
rounded aspect. In a dry climate, under ordinarily favorable conditions for deflation, the same general effects hold true, only in a somewhat different way. Of the positive relief features only the basinal rims can be properly considered. In place of the floor of each basin being intricately dissected by a ramifying system of more or less deep stream valleys, the effects produced in an arid country are as if all valleys of the more familiar lowlands of a humid land were everywhere filled. In order to picture more vividly the broader physiographic features of moist lands, this very procedure is indeed fancied.

With the ideal conception, facts ascertained for the northern Mexican tableland, for instance, seem fully to accord. Hypsometric differences of a mile are not unusual, and these are made possible by the great thicknesses of weak rocks brought by profound faulting into juxtaposition with extensive hard masses. In this region after the removal of the enormous thicknesses of soft materials from the broad belts of weak rocks the sharp ranges of hard mountain rock appear to be just beginning to have their summits notably worn off.

The effect of unlike initial tectonics on the arrangement of the local relief forms at successive stages is pointed out by Davis. ${ }^{44}$ Contrasting a relief of coarse pattern with that of finer type, the region of central Asia is compared with that of western America. In the case of the first the vast even plains of eastern and western Turkestan are separated by a single broadly uplifted mountain belt; in the arid region of southwestern United States many short lofty ranges stud the general plains surface.

\section{IDEAL TYPE OF EARLY ARID STAGE}

The Great Basin, oftenest drawn on in illustration of the youthful stage of relief under influences of aridity, appears to represent a development of a considerable later type of desert topography. The facial expression of the northern Mexican tableland and of the desert regions of southern Arizona and of Sonora seem better to display what is to be expected of the features of this stage after exposure to the protracted arid conditions. With the deflative idea in mind, this region has received more attention than any other in this country. Moreover, its deformational periods are definitely fixed.

Throughout this broad area the alternation of hard and weak rockbelts is of the fine-pattern type. On this account features are presented which enable critical determinations to be made. In one respect the entire region is exceptionally peculiar; the resistant terranes are all segregated at the bottom of the stratigraphic column and the weak rocks

' u Journal of Geologg, vol. xill, 1905, p. 384. 
in great thickness at the top. The principal faulting and folding, on a gigantic scale, is quite ancient-long antedating the last great and recent epeirogenic upraising. With the initiation of the present arid cycle the whole area appears to have been a plains surface with small contrasts of relief-a peneplain to all intents and purposes. As this tract is now about to enter on its mature stage, the extremes of relief presented are between 5,000 and 6,000 feet. Almost ideal conditions and features of arid youth prevail.

\section{CERTAIN OHARACTERISTIC DEFLATIVE FEATURES}

The stage of arid youth presents certain physiographic features more perfectly than are shown at any other period of geographic development. These features it seems impossible to ascribe to an origin by water action. They are characteristics which point most conclusively to windscour as the sole erosive agent in dry climates. Nowhere outside of desert tracts are there known elevated plains of vast extent and even surface. $^{45}$ Only in the arid region do the mountains attain an isolation such as is not approached even by the ideal monadnock; most appropriately the Germans designate the effect the Inselberglandschaft. ${ }^{\mathbf{4}}$ The complete encirclement of mountain by plain finds no counterpart in moist countries. ${ }^{47}$

A noteworthy feature of desert ranges is a general absence of the foothills so inseparably associated with mountains that they are usually looked on as essential elements. Under conditions of aridity plain meets mountain sharply. ${ }^{48}$ The beveled rock-floor of many intermont plains throughout the dry regions is explicable on no known activity of water action in such situations. ${ }^{49}$ Existence of isolated plateau plains rising abruptly out of the general plains surface far from any sight of running water is an anomaly met with only in the desert.50 Notable absence of distinct waterways in the desert basins, even when they have high gradients, bespeaks the utter impotency of water as an erosive agent in an arid climate. ${ }^{51}$

\section{OERTAIN PEOULIARITIES OF ARID TOUTH}

The statement that rock-floors are of common occurrence in the intermont plains of southwestern United States has been recently chal-

s5 Bull. Geol. Soc. America, vol. 19, 1908, p. 63

46 Naturwiss. Wochenschr., n. s., vol. ill, 1904, p. 657.

* Journal of Geology, vol. xvi, 1908, p. 434.

4 Bull. Geol. Soc. America, vol. 19, 1907, p. 572.

40 Ibid., p. 573.

so Proc. Iowa Acad. Sci., vol. xill, 1908, p. 221.

61 American Geologist, vol. xxxiv, 1904, p. 160.

XXXIX-BULL, GmOL. BOC. AM., Vor. 23, 1011 


\section{C. R. KEYES-THE GEOGRAPHIC CYCLE IN AN ARID CLIMATE}

lenged, especially by Tolman. ${ }^{52}$ This writer particularly emphasizes the conditions as they impress him around Tucson, in the Santa Cruz. Valley, in Arizona, as affording conclusive proofs that the plains floor is not a beveled rock surface, but a vast accumulation of wash materials from the contiguous mountains. As is often the case, it appears that in this instance the illustration is not well chosen; that too much dependence has been placed on general impressions and not enough on critical observation. As I remember this locality it presents some unusually good examples of the planed rock-floor but slightly covered by soil. Bearing directly on this point, the neighborhood of the desert laboratory, near Tucson, is particularly instructive. In full corroboration of this statement $\mathrm{McGee}^{53}$ notes that Tolman's "great ideal aprons of colluvial material were really so tenuous as to be entirely worn through in a threeinch deep path leading up to the Tucson Desert laboratory."

It is difficult to see, in view of the numerous recorded observations by many able investigators, why there should be any serious questioning of the existence of a rock-floor in bolsons unless it militate a time-tattered theory. Such planed basins are, to be sure, unlooked for features, and on a moist-climate hypothesis wholly impossible. There is, however, a constantly growing record of rock-floored bolsons. I have recently called attention to some of these features as they are presented in northern Mexico, ${ }^{54}$ in Arizona, ${ }^{55}$ in southern California, ${ }^{56}$ and in Nevada. ${ }^{57}$ Mc$\mathrm{Gee}^{58}$ describes similar phenomena in the Sonoran region of Mexico. In that remarkably dry tract, known as the Mojave Desert, Hershey ${ }^{\text {s0 }}$ makes like observations, which Baker ${ }^{60}$ quite lately fully corroborates. In extensive and systematic searches for undergrand water supplies for railway purposes conducted by me for roads already in operation and lines surveyed in the Southwest during the year 1902 and years following, it was long a constant surprise to find bedrock so thinly covered by soils. One of the most remarkable difficulties in railway construction on the smooth desert plains is the frequent encounter of bedrock in projected grade cuts of only a few feet.

Other arid regions display the rock-floored plains. I well remember so long ago as 1897, during some of the excursions of the Seventh Inter-

\footnotetext{
52 Journal of Geology, vol. xvil, 1909, p. 136.

Communfeation.

st American Journal of Science (4), vol. xv, 1903, p. 207.

os Bull. Geol. Soc. America, vol. 19, 1908, p. 63.

so Trans. American Inst. Mining Eng., vol. xl, 1909, p. 695.

${ }^{67}$ Bull. Geol. Soc. America, vol. 21, 1910, p. 543.

${ }^{68}$ Ibid., vol. 8, 1897, p. 87.

6o Univ. Callfornia Pub., Bull. Dept. Geol., vol. 11i, 1902, p. 4.

- Ibld., vol. v1, 1911, p. 363.
} 
national Geologic Congress, with what utter astonishment I noted in so many localities on the steppes of southern Russia and on the Kirghiz steppes the rock-floor exposed in situations where water could not possibly have operated. Persian deserts left me with similar new impressions. When a little later I had occasion to visit the Saharan region, the bedrock peeping out from under the soils and sands of the Nubian and Lybian deserts convinced me then and there that the true explanation lay not in any phase of water action, for here the annual rainfall was less than one inch. The leveling and general lowering of arid tracts it seemed must be attributable mainly to eolic action, if not to the winds alone. Peneplanation without the aid of water became as real to me then as was peneplanation by means of water.

The alleged enormous depths of basinal wash as reported from time to time in deep well drillings have been already discussed. In all of these cases which I have personally investigated there manifestly have been mistaken for wash materials a great thickness of the little indurated Tertiary beds. In several such instances the Tertiary bedrocks were standing on end and the surface wash was but a few feet in thickness; in other cases the drill began in soft Cretaceous strata and there were reported nearly 2,000 feet of "wash." I do not doubt but there are in many localities wash deposits of considerable thicknesses; but it is also evident that before the usual data, and especially well-logs furnished by the average driller, are to be implicitly depended on they shall have to be critically examined anew in the light of recent determinations.

At a distance and on the hypothesis of normal water action we deductively should expect transferrence of the rock-waste from a basin-rim to central intermont depression. In the absence of direct stream connection with other and lower basins, we likewise should expect great accumulations of finer waste in the middle portions of the higher basins. On a basis of deflation thick basinal deposits are inexplicable; thin soil coverings are demanded. By wind the relief of an arid basin does not appear to be slowly diminished in the beginning by the removal of waste from the highlands and its deposition on the lower gentle slopes or on the basin-bed. In the case of the latter the presence of a rock-floor but thinly veneered by soils seems to be the strongest evidence that the basin itself is being rapidly lowered, not raised. The median line of a basin can hardly be regarded, therefore, a local baselevel of stream action.

In another place ${ }^{61} \mathrm{I}$ have shown that the geologic work of the ephemeral streams, sporadic sheetfloods, and transitory playas of arid plains

ot Bull. Geol. Soc. America, vol. 19, 1908, p. 78. 


\section{C. R. KEYES-THE GEOGRAPHIC CYCLE IN AN ARID CLIMATE}

is not comparable to the water action of moist climates, but that it is as idle as the shifting by the winds of the sands of the seashore. The finer rock-waste disturbed by these agencies is soon borne away by the winds as other soils of the desert. On the evaporation of the broad, thin sheet of storm waters producing playas the bottom muds curl up in thin leaves and are blown away. Playas and similar mud-flats of the arid basins must be considered as areas of rapid denudation and only temporary areas of relatively inconsequential aggradation. ${ }^{\mathbf{2}}$

That subsequent streams in a strictly arid region have so small a chance for development does not appear to be due so much to the fact that the weak substructure of the intermont plains is deeply covered by waste as it is to the more obvious fact that there is not sufficient rainfall to form such streams.

\section{Mature Stage of arid Relief DEDUCTIVE COURSE OF DEVDLOPMENT}

In the modification of the normal geographic cycle to meet the new conditions imposed by an arid climate, several features are especially noteworthy. For the mature stage it is postulated that the continued erosion of the highlands and divides and the continued deposition in the basins produce a coalescence of local drainage systems, headwater erosion of consequent and subsequent streams, and aggradation of higher basins favoring this change; that a beginning is made of the confluence and integration of drainage lines which, when fully developed, characterize maturity; that when the drainage established across a former divide has a strong fall an impulse of revival and deeper erosion makes its way across the aggraded floor of the higher basin, which becomes dissected with bad-land expression; that this dissected floor then is smoothed at a lower level, and that in the last mentioned case the large areas of rockfloor are laid bare. Wind action is given a very subordinate place. In support of these distant deductions I have never found any evidence.

\section{MATURE ARID FEATURES UNDER DEFLATION}

The strongest contrast between the mature relief characteristics of normally moist lands and those of the desert under the influences of arid climate lies in the complete adjustment of consequent and subsequent streamways in the one case and the total absence in the other. The drainage integration which the moist country normally undergoes finds in arid lands no such intricate counterpart.

a Bull. Geol. Soc. America, vol. 19, 1908, p. 84 . 
Of the larger relief features which distinguish maturity in a humid climate none is more conspicuous than a notable rounding of the sharp interstream tracts, hills, and divides and their rapid lowering. In an arid climate this same tendency is even more pronounced. The landscape effect, I take it, is perhaps nowhere so typically developed as in the Great Basin. With the vast planation effects displayed in the intermont areas of this region the sojourner at first is apt to get the erroneous impression so often described, that mountains are there buried up to their shoulders in their own debris. The idea long held that a mountainous tract of interior drainage may be reduced to a plain by the double process of wearing down of the ranges and the filling up of the basins seems not to be very well supported by the latest observations.

The unmistakable deflative features already noted in connection with the discussion of the relief of arid youth are even more pronounced in arid maturity. No known effects of rainfall and stream action can possibly produce the larger features of the relief expression which a region as extensive as the western American dry tract presents; the work accomplished is too prodigious, the time too infinitely long, the space affected too vast. Only by means of the wind under especially favorable circumstances could effects such as we see today be reasonably accomplished. Deflation seems the only explanation which is at all satisfactory.

\section{DEVELOPMENT OF ORIGINAL DRAINAGE LINES IN DESERT REGIONS}

The origin and growth of drainage lines, such as they are, in desert regions under conditions of general aridity is an aspect of erosion which has not, so far as I know, received the critical notice that it appears to deserve. This want of special attention to this single point has done more than anything else to mislead all who have traveled through the mountainous arid tract of America regarding the real ineffectiveness of stream action. Particularly deluding have been the impressions gained in such lands as those of our western country. In. many mountainous belts of that region there is, indeed, an apparent approach to stream effects as they are known in humid climates. Upon this really quite restricted and peculiarly modified effect of normal water work has been based the usual scheme of the arid cycle.

In its broader relations stream action in the mountain belts of arid regions admits of an interpretation of origin wholly different from that commonly held. For example, in the arid region of the northern Mexican tableland it is perfectly conceivable - and I have already set forth the data in support of the idea ${ }^{63}$-that between the initiation of the present

\footnotetext{
63 Journal of Geology, vol, xvil, 1909, p. 31.
} 


\section{6}

C. R. KEYES-THE GEOGRAPHIC CYCLE IN AN ARID CLIMATE

arid cycle and the attainment of the mature stage into which that region is just about to enter the broad belts of weak Cretaceous rocks have been removed to depths of 5,000 feet and over. If at the beginning of the cycle of aridity the original surface were a plain, as there appear to be strong reasons ${ }^{\mathbf{6 4}}$ for believing, the present lofty mountain ranges must have differentially developed through the more rapid deflation of the belts of weak rock now forming the areas of intermont plains; for, as is well known, the stratigraphy of the region is remarkable in that the resistant rocks are mainly segregated in the lower part of the geologic column and the weak rocks are confined to the upper portion.

As the mountains rear their forms more and more above the general plains surface, while the latter is being gradually lowered through deflation, they finally become local rain-provokers of some small influence. During the period of arid youth the streams developed on the mountain slopes become slowly larger and larger and longer and longer until now, as the region is about to enter into its maturity, they attain their maximum size and efficiency. The mountains are now their loftiest, their sides are steepest, into them the intermont plains are encroaching deepest. The moisture gathering about them is greater in amount than at any time before or than will be afterwards. The mountain watercourses reach their greatest extension notwithstanding the fact that they carry relatively little water, are intermittent in character, and their lower reaches seldom pass beyond the foot of the ranges. Instead of being headwater remnants of extensive stream systems which have long since withered away under the influences of arid climate, as is a necessary consequence of the adapted normal cycle hypothesis, they must be regarded as original streams coming into being as the differential relief effects of regional deflation became more and more pronounced. With the advancement of physiographic maturity these streams must begin to wither, and as senile relief approaches they must with few exceptions undergo complete obliteration.

It is the custom to consider all water action upon the desert ranges as normal stream erosion in the process of dissecting recently upraised orographic blocks. This hypothesis seems to fall at once when it is considered that the major faulting of the mountain blocks is, as already stated, mainly very ancient, and not modern, as it has been so long assumed to be.

Certain effects of general deflation have greatly contributed to imparting to the mountain sides the infantile aspects of stream work. As recently suggested, ${ }^{65}$ the locus of maximum lateral deflation in the desert

at Proc. Iowa Acad. Scl., $\nabla 01$, xtli, 1908, p. 221.

os Sclence, n. s., vol, xxix, 1909, p. 753. 
ranges is their base, where plain sharply meets mountain without the intervention of foothills. The hard mountain rock is encroached upon at the level of the general plains surface as the sea gnaws away a line of its bordering cliffs, until, in many instances at least, the surface of the intermont plain extends into the mountain blocks distances of several miles. No more astonishing revelation was ever experienced by one who, on first entering the arid region of the West thoroughly believing in the prevailing theory of basin-range structure, was compelled to admit the facts so clearly presented that the sharp, straight line of meeting of mountain and plain was not a faultscarp at all, and that the major line of displacement was usually situated several miles out on the basin plain. ${ }^{86}$

If the deflative hypothesis of regional desert-leveling and lowering be accepted we have in the desert ranges a stream type hitherto unrecognized. The streams of this class have no history previous to the youthful stage of the present arid cycle; they have no prospect of relations with streams of any later cycle. Their birth, their span of life, their extinguishment are definitely circumscribed. They are the only existing streams we know of that do not have some sort of inherited relations with the waters of previous geographic cycles. They are the only streams the complete life histories of which may be distinctly traced at every stage. They are the only streams where origin is clearly fixed in time and sharply limited in space.

\section{DURATION OF ARID MATURITY}

The period of transition from arid youth to arid old age must be exceedingly brief. Compared with the corresponding stage of the normal moist-climate cycle it is almost ephemeral. So short is it that it can hardly be recognized as a distinct stage. Strongly supporting this conclusion are recent observations in New Mexico, Arizona, and Sonora.

As the broad belts of weak rocks, previously profoundly faulted, undergo through deflative influences the enormous denudation so manifest on every hand, the effect is not only rapidly to wear them down, but the narrower belts of resistant mountain rock are also encroached on as the latter are brought into stronger and stronger relief. In the case of the region just mentioned, where thicknesses of upward a mile have been removed, the hard masses of mountain rock have been eaten into at the base of the ranges for distances of 3 to 5 miles, and even more. There is thus left a lofty central ridge with precipitous slopes rising out of the plains as volcanic isles out of the sea.

Titles as the Organs, the Needles, the Castle Domes, and the Eagle Tails, locally applied to some of the desert ranges, well express the strik-

Science, n. s., vol. xxxili, 1911, p. 466. 
ing topographic aspects of the landscape. A generalized cross-section, based on the geologic structure of the Sierra de los Caballos, in New Mexico, indicates the common relations of relief and tectonics (figure 1). The perfect independence of the two are fully discussed in another

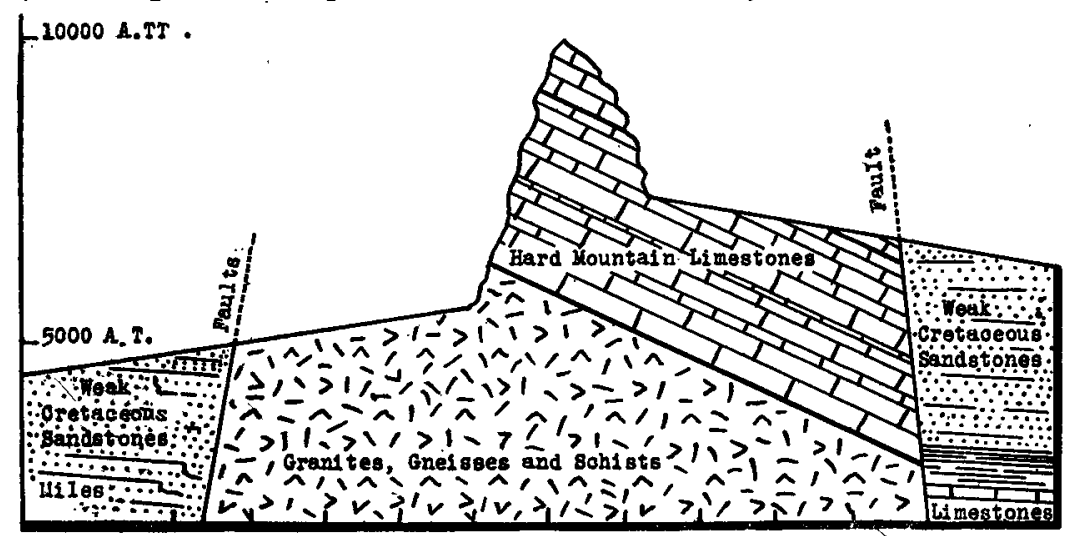

Figurg 1.-Passing of arid Fouth: Rim of a Desert Basin

place. ${ }^{67}$ Another good example of the final mural ridge is that of the Palomas range, in southwestern Arizona, standing above the main mountain block more than 1,000 feet (figure 2).

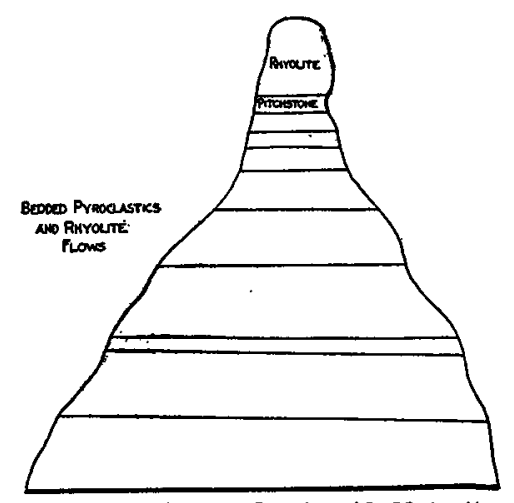

Frgure 2.-Approach of aria Maturity: Last of a Desert Range

After the youthful stage here represented the upper remnantal portion of the mountain block is rapidly removed and reduced to a low, rounded mound projecting but slightly above the level of the general plains surface. Transformation from youth to old age is quick, decisive, complete. The apparently graded plains on either side of the old ridge gives it the aspect of a worn-down mountain buried to its shoulders in the waste of its own substances. In the case of the Caballos, already mentioned, the rock-floor of the plains is not confined merely to the higher parts of the piedmont slopes, as has been explained by Davis, ${ }^{68}$ but extends for. 30 miles across the intermont plain of the Jornada del Muerto to the next desert range to the east-the Sierra San Andreas. ${ }^{69}$

or Bull. Geol. Soc. America, vol. 21, 1910, p. 543.

es Journal of Geology, vol, xili, 1905, p. 387.

U. S. Geol. Survey Water Supply and Irrigation Papers, No. 123, 1905, p. 12. 
The Great Basin appears to be a region long subjected to deflative influences that is passing through the mature stage.

\section{Prevalence of old Age in Desert Regions POSTULATED CHARACTERISTICS}

According to the normal standard adapted to arid conditions, topographic old age begins to set in when a general reduction of the highlands gives rise to a notable decrease in rainfall and consequently stream action, and the process of drainage disintegration commences to predominate. Only at this time is wind-scour admitted to be at all effective.

\section{TOPOGRAPHTC FEATURES OF OLD AGE UNDER DEFLATION}

The drainage features of the latter part of the arid cycle may be entirely neglected. Topographic expression alone can be considered. Compared with that of maturity, there are scarcely any contrasts of relief. Desert lowering will be much slower because weak rocks will have been already largely removed. There is greater homogeneity of texture and hardness in the older rocks than in the more recently formed sediments, and consequently less opportunity for marked differential effects.

The prevailing relief expression in arid lands must necessarily be that of old age. The rapidity with which the several parts of an arid region passes through the different relief stages depends partly on the stratigraphic segregation of the hard as well as the soft rocks, partly on the character of the deformation, partly on the nature of the geotectonic pattern, and partly on the degree of aridity. Thus it is that under the same climatic conditions a certain provincial difference in the tectonics of the Mexican tableland, the Great Basin, and the Colorado plateau of Arizona permits the first to represent arid youth, the second arid maturity, and the third arid old age.

\section{Baselevel of Eolian Erosion}

The remarkable plains-forming tendency of deflation in dry regions is one of its main characteristics. ${ }^{70}$ As already noted, the plain is the dominant relief feature from the very beginning of the arid geographic cycle; in a humid climate it only becomes notably developed at the very end. When Passarge ${ }^{71}$ was conducting his investigations in the South African deserts he long had difficulty in understanding how it was possible under conditions of arid climate for general planation of vast tracts to go on without regard to sealevel, since the wind was thought to have no baselevel of erosion. So long as the waters of the sea are kept out, Penck ${ }^{72}$ argued that deflation could go on indefinitely below sealevel.

70 Popular Sctence Monthly, vol. 1xxiv, 1909, p. 23.

TI Zeitsch, d. deut. geol. Gesellsch., vol. Ivi, Protokol, 1904, p. 191. 
There appears to be, as recently shown, ${ }^{73}$ a downward limit even to desert-leveling and eolic excavation. The ground-water level in each structurally inclosed basin must finally put a stop to wind-scour by keeping the surface above it moist, giving rise either to salinas or forming a basin into which sporadic storm waters find a long resting place. ${ }^{74}$

In illustration, many of the salinas of the dry region of western America might be enumerated. The lakes of Death and Imperial valleys, both below sealevel, in southern California; the basin of Lake Eyre, in Australia, the Sea of Aral, and other similar bodies of water in arid Asia are most notable. On a somewhat smaller scale are many of the lakelets of the Mexican tableland. Of these the Sandoval, the Hueco, the Casa Grande, and the Mapimi bolsons are best known. ${ }^{75}$ The first of these ${ }^{76}$ is the highest and driest bolson of the Mexican tableland within the boundaries of the United States. Its surface is 6,000 feet above the sea. Its center is occupied by a great chain of dry and bitter lakes. In all of its vast area and during a period of 400 years since the earliest occupation of the country by Europeans only two small springs of potable water were known within its confines. Recently it was inferred from the general character of the broad basin, its geologic structure, and the location of the two springs, that ground-water level at certain places must be very close to the surface. Proceeding on this hypothesis, several test wells were put down and the inferences found to be correct. At once there was excavated an area of several acres in extent for reservoir purposes. Now there stands a fine large body of soft water, the surface of which comes within a few feet of that of the surrounding plain. Around the lakelet a prosperous town has sprung up.

Depressions of the Saharan region appear to be downwardly arrested by ground-water level. Beadnell, ${ }^{77}$ in describing the Kharga oasis, explains the presence of lake beds in the hollow by the uncovering of impervious clay strata and the consequent exposure of the surface-water sandstone with its artesian supplies. Long ago Lyons ${ }^{78}$ called attention to similar phenomena in the Nile Valley, but the springs thus let loose were regarded by him as increasing local erosion.

\section{Normal Water Action in Desert Regions}

The derivation of the larger relief features of the arid regions through means of deflation does not necessarily preclude all normal sculpturing

\footnotetext{
72 American Journal of Science (4), vol. xix, 1905, p. 167.

78 Journal of Geology, vol. xvil, 1909 , p. 661.

74 American Journal of Science (4), vol. xvi, 1903, p. 377.

${ }^{75}$ Bull. Geol. Soc. America, vol. 19, 1908, p. 91.

te Journal of Geology, vol. xvi, 1908, p. 434.

" Geological Magazine, n. s., decade $\nabla$, vol. vi, 1909, p. 476.

${ }^{78}$ Quart. Jour. Geol. Soc. London, vol. 1, 1894, p. 531.
} 
by water. The extent and character of water action are fully considered later. From the very nature of the special climatic conditions imposed by aridity, it follows that the erosional effects of the aqueous agencies must be reduced far below what is commonly expected of them. It is customary to regard desert landscapes as examples of normal water corrasion identical in origin with those of moist climates except that it is perhaps somewhat less rapid. In the present connection the importance of water action in matters of landscape details is not questioned; but the very secondary influence of stream corrasion in its broader operations is premised, and as a general erosional agency the dominance of windscour is recognized. Quantitative data on the relative efficiencies of the two processes are at hand and they are discussed at length in another place. Here the general results need be only briefly anticipated.

Water action in desert regions assumes three distinctive aspects: That produced by the through-flowing rivers, that of the intermittent torrential arroyos of the mountains, and that of the rare and brief sheetfloods. It is the second of these phases which mainly attracts the attention of the sojourner from less parched parts of the world. With a natural proneness to extend his moist-climate conceptions, the impression is at first gained that nowhere else is there so eloquent attest of energetic storm work as is presented on the desert ranges. Indeed the dominant characteristic of the arid sierras is notable ruggedness. It is apparently the same type of ruggedness which in moist-climate countries is by general consent ascribed to vigorous stream work on a recently upraised mountain tract.

Preconceived notions concerning general erosional effects under moistclimate conditions can not be in toto successfully transplanted to arid lands. The sharp meeting of plain and mountain without the intervention of foothills is certainly not a marked characteristic of water sculpturing in the mountains of moist climates. With much less amount of water involved, how may it be plausibly converted into a conspicuous feature in dry regions? The Castle Domes, Eagle Tails, Harquahalas, and Plomas ranges of southwestern Arizona are notable examples. In cliffs, picachos, minor and major crests they rise steeply out of the general plains surface. Yet the annual rainfall of this district is less than 3 inches. Instead of being distinctive forms produced solely by water action, there appear to be nowhere else so conspicuous illustrations of general undercutting of hard masses of mountain rock by the wind armed with sharp sands and aided by insolation. The locus of maximum lateral deflation action, as has been recently shown, ${ }^{79}$ is at the level of the general

79 Science, n. s., vol, xxix, 1909, p. 752. 


\section{C. R. KEYES-THE GEOGRAPHIC CYCLE IN AN ARID CLIMATE}

plains surface, and this is constantly lowering. This feature is especially well shown in the Caballos and Plomas ranges (figures 1 and 2). On the basis of water action alone, the most inexplicable feature of desert configuration has always been how around the periphery of a mountain block a broad, perfect plain is produced, while in the middle a lofty, rugged mountain ridge exists. In the light of the changed angle at which the facial expression of the desert ranges is viewed, the alleged evidences of energetic storm work have to be critically examined anew. Bearing directly upon this point, it is not without great interest to note an expression of opinion by the late S. F. Emmons, than whom no one was probably more familiar with the arid regions of the West during a period covering more than 40 years. In the spring of 1903 , when he was paying me a fortnight's visit at Socorro, he remarked that he was completely nonplussed that the desert mountain ranges should present such youthful topography on so huge a scale, and yet display so little evidence of adequate means with which to accomplish it; and he further stated, concerning the unsatisfactory character of all existing explanations, that.in all his long experiences in the West this feature was the most puzzling of any which he had encountered or which had ever confronted geologists. At that time I had already followed the aqueous development of the relief features of the region to its necessary and wholly inadequate conclusions, and $I$ had already begun to grasp the fundamental significance of the rock-floors of the arid intermont plains and the tremendous efficiency of wind-scour upon dry rock surfaces. Near the conclusion of the long discussions which this view aroused, Mr. Emmons dropped the statement that the conception was too new for him to grasp all at once, but that he believed that there was great merit in the wind explanation. It was, however, a full lenstrum before he told me one day that he had come to believe that the only adequate solution of the vexed problem would be through means of the wind and not water.

\section{RECAPITULATION}

The larger geographic features of deserts appear to find no adequate explanation of their origin by any known method of stream corrasion. For them wind-scour alone satisfactorily accounts. The necessary consequences of a strictly deflative hypothesis for the genesis of desert landscapes is everywhere amply supported by recently recorded observations. The geographic cycle in an arid climate is logically developed by considering wind action and not water action as the prime erosional process. For topographic detail important water action of normal character is not precluded. 
Downloaded from gsabulletin.gsapubs.org on July 30, 2015 


\section{Geological Society of America Bulletin}

\section{Deflative scheme of the geographic cycle in an arid climate}

CHABLES R. KEYES

Geological Society of America Bulletin 1912;23, no.

1;537-562

doi: 10.1130/GSAB-23-537

Email alerting services

Subscribe

Permission request click

www.gsapubs.org/cgi/alerts to receive free e-mail alerts when new articles cite this article

click

www.gsapubs.org/subscripti ons/ to subscribe to Geological Society of America Bulletin

click

http://www.geosociety.org/pu bs/copyrt.htm\#gsa to contact GSA

(C) 1912 Geological Society of America

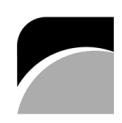

THE GEOLOGICAL SOCIETY OF AMERICA 
Copyright not claimed on content prepared wholly by U.S. government employees within scope of their employment. Individual scientists are hereby granted permission, without fees or further requests to GSA, to use a single figure, a single table, and/or a brief paragraph of text in subsequent works and to make unlimited copies of items in GSA's journals for noncommercial use in classrooms to further education and science. This file may not be posted to any Web site, but authors may post the abstracts only of their articles on their own or their organization's Web site providing the posting includes a reference to the article's full citation. GSA provides this and other forums for the presentation of diverse opinions and positions by scientists worldwide, regardless of their race, citizenship, gender, religion, or political viewpoint. Opinions presented in this publication do not reflect official positions of the Society.

\section{Notes}

(C) 1912 Geological Society of America

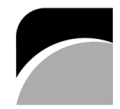

THE GEOLOGICAL SOCIETY 